\title{
Should the UK introduce varicella vaccine?
}

\section{Marion Roderick, Athimalaipet V Ramanan, Adam Finn}

\section{Perspective on the paper by Cameron et al (see page 1062)}

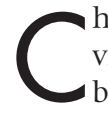
hickenpox has traditionally been viewed as an irritating but inevitable infection to be endured during childhood, a rite of passage during the preschool years. This benign view persists despite evidence that certain groups, including neonates, adults, pregnant women and the immunocompromised, have higher risk of severe disease. Few data on the incidence of severe complications and death in children are available; however, such information might change our view of the disease, especially considering that such morbidity and mortality may now be regarded as vaccine preventable.

Population incidence is approximately 13-16 cases per 1000 with substantial year-to-year variation with 2-5-yearly epidemics. ${ }^{1}$ Recently, incidence in preschool children has risen relative to primary school age children, possibly due to the increased mixing at child-care centres and playgroups. ${ }^{2}{ }^{3}$ For every 1000 cases of varicella, between two and five will require hospital admission, ${ }^{24-6}$ with the majority being children, reflecting higher childhood incidence.

Secondary bacterial infections, usually affecting skin and soft tissue, are the most common complications..$^{78}$ However, as the vast majority are presumably treated in primary care without hospital attendance, the true incidence is uncertain. Skin lesions also provide a portal of entry for more invasive infections including arthritis, osteomyelitis, necrotising fasciitis, sepsis and other deep-seated infections caused mainly by Group A $\beta$ haemolytic Streptococci and Staphylococcus aureus. ${ }^{8}$ Chickenpox was a factor in 15 out of 26 paediatric cases of Group A streptococcal necrotising fasciitis in a recent study. ${ }^{9}$ Central nervous system complications include cerebellar ataxia (approximately one in 4000 cases), meningoencephalitis, meningitis and vasculitis, which may result in strokes. ${ }^{10}$ The latter may occur late and may thus not be recognised as linked either in studies or in clinical practice.

In this issue, Cameron et al ${ }^{11}$ describe 112 children with severe complications of chickenpox reported over a 13-month period $(0.82 / 100000$ children per year). Most were healthy children without identifiable risk factors for severe disease and rates were highest in 0-4-year-old children, the age group in which varicella is most common. The methodology ascertained a small proportion of the most severe hospitalised cases and a further 28 children with a variety of serious complications which were outside the study definitions were ascertained but excluded from analysis. One intrauterine and five postnatal deaths were identified, four in children with underlying medical conditions although not ones strongly associated with high varicella mortality.

The message that emerges from this and previous studies is that severe and fatal varicella occurs predominantly in children in whom one would not predict problems but who could be protected, in most cases directly, by universal immunisation starting around l year of age. However many countries, including the UK, only recommend vaccine for certain high risk groups or their healthy susceptible contacts. ${ }^{3}$

In contrast, universal childhood varicella immunisation has been introduced elsewhere, most notably the United States, while in Europe it has only been recommended in Germany to date. Experience in the USA over the last decade has taught us a lot. From 1995 to 2000 , cases declined by around $80 \%$, the largest reductions being in children aged 1-4 years. Concomitant reductions in infants and adults confirmed reduced transmission (herd immunity). ${ }^{12}$ Hospital admissions declined and mortality rates dropped by $66 \%$, from an average of 0.41 death per 1 million population during 1990-1994 to 0.14 during 1999-2001 $(\mathrm{p}<0.001)$. The greatest reduction in mortality (92\%) was observed, again, among children 1-4 years of age. More recently, varicella outbreaks have been reported particularly in school populations with high uptakes. Overall, attack rates among vaccinated children were generally $11-17 \%$ but exceptionally were as high as $40 \% .{ }^{13}$ Such "break-through infections" resulted in milder but contagious illness presenting a risk to susceptible individuals. ${ }^{14}$ Clearly, a single vaccine dose in the second year of life fails to protect $15-20 \%$ of recipients and there is some evidence of waning immunity. ${ }^{15}$ Consequently, a second routine dose of vaccine is now recommended. ${ }^{16}{ }^{17}$

As vaccinated children are less likely to develop shingles, ${ }^{18}{ }^{19}$ in the long term the incidence of shingles should fall in an immunised population. ${ }^{20}$ However, exposure to wild chickenpox in the community may boost immunity levels, suppressing the reactivation of the virus. ${ }^{21}$ Therefore, people who have had wild-type chickenpox might get more shingles once herd immunity starts to bite. Some studies have shown an increase in shingles since vaccination began, ${ }^{22-24}$ although rates of shingles were thought to be increasing before varicella vaccination commenced $^{325}$ and one large recent study did not demonstrate a rise. ${ }^{26}$ Either way, zoster is also preventable by immunisation: a vaccine containing higher titres of vaccine virus than the childhood vaccine has been shown to be effective in preventing herpes zoster and post-herpetic neuralgia ${ }^{27}$ and has been recommended for universal use in persons 60 years of age or older since 2006 in the USA. ${ }^{28}$

So what about adding a two dose course of varicella vaccine to the UK schedule now? The available formulations are the single antigen vaccine and a combination vaccine against measles, mumps, rubella and varicella (MMRV). Seemingly, the simple, obvious and easy thing to do is to switch from MMR to MMRV. There would be no extra trouble or delivery costs, just the difference between the purchase costs of the two vaccines and doubtless the NHS could negotiate a good price for so many doses. However, this ignores the ongoing damage inflicted on public confidence by the MMR scare and its apparently endless reiterations. Despite abundant evidence that MMR vaccine is safe and a total absence of any evidence that splitting it into its component parts has any merit, fears regarding both issues continue to be raised and publicised. In this context, there has to be genuine concern that an MMRV programme could result in suboptimal uptake, further damage to the MMR programme and ineffective varicella herd immunity with an epidemiological shift of disease to older age groups and possible increased morbidity due to the higher risk of complications in adults.

The immediate task is therefore to repair the damage done to an understandably confused public, preceded by 
some systematic work to establish how best such communication can be achieved, and followed by some careful assessment of the potential acceptability of the MMRV vaccine. In the meantime, a temporary strategy of immunising all teenagers without a history of chickenpox could be implemented without fear of altering the epidemiology of chickenpox. This could prevent cases of severe disease in adults and pregnant women and raise public awareness of the potential and desirability of primary prevention. ${ }^{29}$

Arch Dis Child 2007;92:1051-1052.

doi: 10.1136/adc.2007.130518

Authors' affiliations

Marion Roderick, Athimalaipet V Ramanan,

Bristol Royal Hospital for Children, United Bristol Healthcare Trust, Bristol, UK

Adam Finn, Department of Clinical Science at South Bristol, University of Bristol, Bristol, UK

Correspondence to: Adam Finn, Institute of Child Life and Health, Level 6, UBHT Education Centre, Upper Maudlin St, Bristol BS2 8AE, UK

Adam.Finn@bristol.ac.uk

Competing interests: AF has undertaken advisory work for, chaired and spoken at symposia organised by and accepted support to attend scientific meetings from all the major vaccine manufacturers. Payments for these activities have been made to his employer, the University of Bristol and used to pay for research and training materials and activities.

\section{REFERENCES}

1 Heininger U, Seward JF. Varicella. Lancet 2006;368(9544):1365-76.
2 Bramley JC, Jones IG. Epidemiology of chickenpox in Scotland: 1981 to 1998. Commun Dis Public Health $2001 ; 3(4): 282-7$

3 Brisson M, Edmunds WJ, Law B, et al. Epidemiology of vericella zoster virus infection in Canada and the United Kingdom. Epidemiol Infect 2001;127:305-14.

4 Galil K, Brown C, Lin F, et al. Hospitalizations for varicella in the United States, 1988 to 1999. Pediatr Infect Dis J 2002;21:931-5.

5 Boelle PY, Hanslik T. Varicella in non-immune persons: incidence, hospitalization and mortality rates. Epidemiol Infect 2002;129:599-606.

6 Ratner AJ. Varicella-related hospitalizations in the vaccine era. Pediatr Infect Dis J 2002;21:927-30.

7 Grimprel E, Levy C, de La Rocque F, et al. Paediatric varicella hospitalisations in France: a nationwide survey. Clin Microbiol Infect 2007;13(5):546-9.

8 Guess HA, Broughton DD, Melton L III, et al. Population-based studies of varicella complications. Pediatrics 1986;78:723-7.

9 Eneli I, Davies HD. Epidemiology and outcome of necrotizing fasciitis in children: an active surveillance study of the Canadian Paediatric Surveillance Program. J Pediatr 2007;151(1):79-84.

10 Askalan R, Laughlin S, Mayank S, et al Chickenpox and stroke in childhood: a study of frequency and causation. Stroke 2001;32:1257-62.

11 Cameron JC, Allan G, Johnston F, et al. Severe complications of chickenpox in hospitalised children in the UK and Ireland. Arch Dis Child 2007;92:1062-6.

12 Seward JF, Watson BM, Peterson CL, et al. Varicella disease after introduction of varicella vaccine in the United States, 1995-2000. JAMA 2002;287:606-11

13 Tugwell BD, Lee LE, Gillette H, et al. Chickenpox outbreak in a highly vaccinated school population. Pediatrics 2004; 1 13:455-9.

14 CDC. Vaccines \& immunizations: Varicella Active Surveillance Project. http://www.cdc.gov/ vaccines/stats-surv/vasp/default.htm (accessed 12 September 2007).

15 Chaves SS, Gargiullo P, Zhang JX, et al. Loss of vaccine-induced immunity to varicella over time. N Engl J Med 2007;356(11):1121-9.

16 Lopez AS, Guris D, Zimmerman L, et al. One dose of varicella vaccine does not prevent school outbreaks - is it time for a second dose? Pediatrics 2006; 117:1070-7.
17 Gershon AA. Varicella vaccine-are two doses better than one? N Engl J Med 2002;347 1962-3.

18 Hardy I, Gershon AA, Steinberg SP, et al. The incidence of zoster after immunization with live attenuated varicella vaccine. A study in children with leukemia. N Engl J Med 1991;325:1545-50.

19 Centers for Disease Control and Prevention. National, state, and urban area vaccination coverage among children aged 19-35 monthsUnited States, 2004. MMWR Morb Mortal Wkly Rep 2005:54:717-21

20 Brisson M, Edmunds WJ, Gay NJ, et al. Modelling the impact of immunization on the epidemiology of varicella zoster virus. Epidemiol Infect 2000;125:651-69.

21 Thomas SL, Wheeler JG, Hall AJ. Contacts with varicella or with children and protection against herpes zoster in adults: a case control study. Lancet 2002;360:678-82

22 Yih WK, Brooks DR, Lett SM, et al. The incidence of varicella and herpes zoster in Massachusetts as measured by the Behavioral Risk Factor Surveillance System (BRFSS) during a period of increasing varicella vaccine coverage, 1998-2003. BMC Public Health 2005;5:68.

23 Mullooly JP, Riedlinger K, Chun C, et al. Incidence of herpes zoster, 1997-2002. Epidemiol Infect 2005;133:245-53.

24 Chaves SS, Santibanez TA, Gargiullo P, et al Chickenpox exposure and herpes zoster disease incidence in older adults in the U.S. Public Health Rep 2007;122(2):155-9.

25 Centers for Disease Control and Prevention. Decline in annual incidence of varicella-selected states, 1990-2001. MMWR Morb Mortal Wkly Rep 2003:52:884-5.

26 Jumaan AO, Yu O, Jackson LA, et al. Incidence of herpes zoster, before and after varicellavaccination-associated decreases in the incidence of varicella, 1992-2002. J Infect Dis 2005;191:2002-7

27 Oxman MN, Levin MJ, Johnson GR, et al. A vaccine to prevent herpes zoster and postherpetic neuralgia in older adults. N Engl J Med 2005;352:2271-84.

28 Mitka M. FDA approves shingles vaccine: herpes zoster vaccine targets older adults. JAMA 2006;296(2): 157-8

29 Sengupta N, Booy R, Schmitt HJ, et al. Varicella vaccination in Europe: are we ready for a universal childhood programme? Eur J Pediatr, 2007 Mar 3 [Epub ahead of print]. 